\title{
Tribological performances of elliptic and circular texture patterns produced by innovative honing process
}

\author{
M. Yousfi*, S. Mezghani, I. Demirci, M. El Mansori \\ Arts et Métiers ParisTech, MSMP, Rue Saint Dominique, Châlons-en-Champagne, France
}

\begin{abstract}
A B S T R A C T
Honing is a manufacturing process which uses friction and abrasion mechanisms at a reduced velocity to print a multiscale and anisotropic texture on the liner surface of automotive engines. It enables to enhance the functional performances of a ring-pack system. However, industrial honing basically generates cross-hatched rectilinear textures. This paper proposes new surface textures, generated by an innovative honing prototype machine, with original patterns (circles and ellipses) at different size and aspect ratio. Then, the friction performances of each generated surface are evaluated using a reciprocating ring-liner tribometer and compared with industrial helical slide honed (HSH) texture. The results

show that ellipse patterns oriented at ring sliding direction contribute the most to reduce the friction coefficient.
\end{abstract}

Keywords:

Honing

Surface texture

Friction

Cylinder liner

\section{Introduction}

In an automotive industry, manufacturing low emission engines with optimized performances is a major objective. The cylinder surface texture has a high contribution towards engine functional performances (friction, oil consumption, wear, etc.). This texture is generated by three superfinishing honing process stages (rough honing, finish honing and plateau honing). Different honing techniques are used in industry such as Plateau Honing $(\mathrm{PH})$, Helical Slide Honing (HSH) and Slide Honing (SH). They generate cross-hatched textures with different surface roughness and anisotropy [1-3].

Two optimal honing cross-hatched angle ranges ([25-55 ${ }^{\circ}$ and $\left.\left[120-140^{\circ}\right]\right)$ for friction reduction were identified by ring liner simulation models [4,5] and friction test rig [2,6]. Engine tests $[1,7,8]$ confirmed these two groove orientations. They correspond to that generated by $\mathrm{PH} / \mathrm{SH}$ and $\mathrm{HSH}$ processes, respectively. Nevertheless, HSH honed surface (cross-hatched orientation of about $\left[120-140^{\circ}\right]$ ) has shown better functional performances. On the one hand, their friction losses are lower and less sensitive to roughness amplitude than PH surfaces $[2,4,9]$. An experimental study using a tribometer showed a friction reduction until $20 \%$ of $\mathrm{HSH}$ texture in comparison to $\mathrm{PH}$ surface [2]. On the other hand, HSH contributes to lower oil consumption. Some studies using engine tests showed an oil consumption reduction greater than $40 \%$ for HSH surface in

\footnotetext{
* Corresponding author.

E-mail address: mohammed.yousfi@ensam.eu (M. Yousfi).
}

comparison to PH one $[1,7,10]$. Unfortunately, only cross-hatched rectilinear texture patterns can be basically generated with abrasive honing, due to the kinematics industrial honing machine capabilities [11].

Moreover, original surface patterns form and size, like circle and ellipses cavities, generated experimentally by etching, Laser Surface Texturing (LST) process or simulated numerically using virtual texturing approach have shown improved functional performances (friction, lubrication) in comparison to abrasive industrial honed surface texturing (SH or $\mathrm{PH})$ ) [6,12-17].

However, abrasive industrial honing has an advantage to be more reliable, with a good repeatability in mass production and reduced manufacturing costs, compared to other surface finishing and texturing processes such as Laser Surface Texturing (LST) or Ultraviolet (UV) laser [1].

In this paper, new texture patterns are generated (circles and ellipses) using abrasive honing process through an innovative honing prototype machine, open for texture programming and with enhanced kinematics [18]. For that, different honing kinematics are used in order to obtain circular and elliptical patterns at different size and aspect ratio (perpendicular ellipse axis/longitudinal ellipse axis ratio).

Then, the friction performance of each generated surface is evaluated at different lubrication conditions with a reciprocating ring-liner tribometer. The obtained results show the contribution of pattern size and orientation (of major ellipse axis) on friction performances. Finally, friction reduction of these original textures is compared to an optimized industrial texture (HSH). 


\begin{tabular}{|c|c|c|c|}
\hline \multicolumn{2}{|c|}{ Nomenclature } & \multirow{2}{*}{$\begin{array}{l}\text { STE } \\
\mu_{\mathrm{D}}\end{array}$} & \multirow{2}{*}{$\begin{array}{l}\text { small size elliptical texture patterns oriented at the } \\
\text { transverse direction of sliding direction } \\
\text { lubricant viscosity, Pa.s }\end{array}$} \\
\hline$S_{\mathrm{pk}}$ & $3 \mathrm{D}$ roughness parameter for reduced peak height $(\mu \mathrm{m})$ & & \\
\hline$S_{\mathrm{k}}$ & $\begin{array}{l}\text { 3D roughness parameter for depth of the roughness } \\
\text { core profile }(\mu \mathrm{m})\end{array}$ & $\begin{array}{l}v \\
F_{\mathrm{N}}\end{array}$ & $\begin{array}{l}\text { mean sliding velocity during friction tests } \\
\text { normal contact force between ring and liner surface }\end{array}$ \\
\hline$S_{\mathrm{vk}}$ & $\begin{array}{l}\text { 3D roughness parameter for the reduced valley depth } \\
(\mu \mathrm{m})\end{array}$ & $F_{\mathrm{T}}$ & $\begin{array}{l}\text { tangential contact force between ring and liner } \\
\text { surface }\end{array}$ \\
\hline SC & small size circular texture patterns & $l_{\mathrm{y}}$ & contact width between ring and liner surface \\
\hline $\mathrm{BC}$ & big size circular texture patterns & $\mathrm{HSH}$ & helical Slide Honing or Helical Slide Honed (surface) \\
\hline \multirow[t]{2}{*}{ BLE } & big size elliptical texture patterns oriented at the & $\mathrm{COF}$ & coefficient of friction \\
\hline & longitudinal direction of the ring sliding direction & $S$ & average Sommerfeld number $S=\frac{\mu_{\mathrm{D}} \times \mathrm{v}}{F_{\mathrm{N}} / l_{\mathrm{y}}}$ \\
\hline \multirow[t]{2}{*}{ SLE } & small size elliptical texture patterns oriented at the & $R 1$ & radius of first ellipse arc \\
\hline & longitudinal direction of the ring sliding direction & $R 2$ & radius of second ellipse arc \\
\hline \multirow[t]{2}{*}{ BTE } & big size elliptical texture patterns oriented at the & $X$ & ellipse width (on the transverse direction of sliding) \\
\hline & transverse direction of sliding direction & $Y$ & ellipse length (on the sliding direction) \\
\hline
\end{tabular}

\section{Experimental procedure}

\subsection{Honing experiments}

Flexible honing experiments have been carried out on an instrumented vertical prototype honing machine with an expandable tool (Fig. 1) in order to generate innovative circular and elliptical texture patterns. Moreover, an HSH texture pattern is generated for comparison. The considered part is a gray cast iron cylinder liner for combustion engines with a diameter of $72.2 \mathrm{~mm}$ and a height of $127 \mathrm{~mm}$.

Table 1 describes the general honing operating conditions. First, during the rough honing stage, enough material is removed to reach the desired cylindricity. At this stage, all of the process parameters are kept constant for all the honed bores. Then, for the finish stage, which enables to obtain the desired texture patterns, different kinematics are used in order to obtain circular and elliptical grooves pattern at different sizes and orientations. Finally, the third stage (plateau stage) is used to obtain plateaued surface textures $[2,19]$. Each texture was generated at least three times.

Three different texture anisotropies with two size levels ( $R m \sim 7.5 \mathrm{~mm}$ and $R m \sim 14 \mathrm{~mm}$ for the small and big size respectively) were generated and considered in this study and compared to an HSH surface

1. Small size circular patterns (SC).

2. Big size circular patterns (BC).

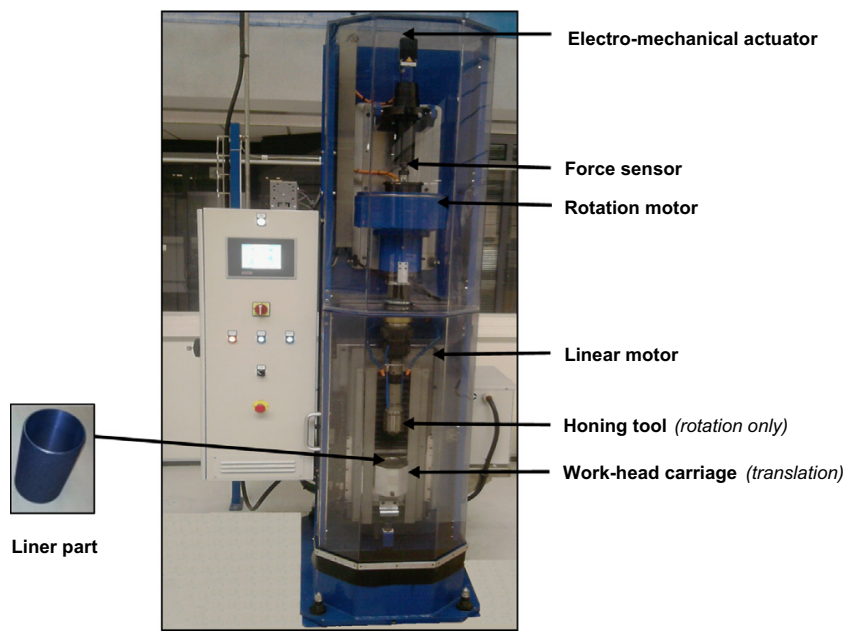

Fig. 1. Vertical honing prototype machine with an expansible tool.
3. Big size elliptical texture patterns oriented at the longitudinal direction of the ring sliding direction (BLE).

4. Small size elliptical texture patterns oriented at the longitudinal direction of the sliding direction (SLE).

5. Big size elliptical texture patterns oriented at the transverse direction of sliding direction (BTE).

6. Small size elliptical texture patterns oriented at the transverse direction of sliding direction (STE).

To generate circular and elliptical trajectory, the prototype machine use an ISO programming mode which has the advantage to synchronize rotation motion to stroke motion using a circular interpolation $[11,18]$. For circular pattern a series of circular arc at the same radius is generated (Fig. 2(a)). For elliptical patterns a series of two tangent circular arcs at different radius ( $R 1$ and $R 2)$ is made (Fig. 2(b) and (c)). The orientation of ellipses (longitudinal or transverse) depends on the radius and length of each circular arc.

The size is evaluated using the mean radius $\mathrm{Rm}$ expressed by:

$R m=\frac{X / 2+Y / 2}{2}$

Where $X$ and $Y$ are the width (transverse to the sliding direction) and the length (on the sliding direction) respectively, as shown in Fig. 2. Furthermore, surface patterns orientation can be evaluated by the $X / Y$ ratio $(X / Y=1$ for circles, $X / Y>1$ for transverse ellipses and $X / Y<1$ for longitudinal ellipses).

Table 2 resumes the kinematics honing operating conditions for the different circular and elliptical textures.

For the HSH texture, the classic honing mode is used, like industrial honing machines [2,9,19], with a rotation speed of $70 \mathrm{rpm}$ and an axial velocity of $38 \mathrm{~m} / \mathrm{min}$.

Table 1

General honing operating conditions.

\begin{tabular}{llll}
\hline Honing parameters & $\begin{array}{l}\text { Rough } \\
\text { honing }\end{array}$ & $\begin{array}{l}\text { Finish } \\
\text { honing }\end{array}$ & Plateau step \\
\hline Cutting speed $(\mathrm{m} / \mathrm{min})$ & 49 & 22 & 22 \\
Contact force $(\mathrm{N})$ & 800 & 700 & 250 \\
Honing duration $(\mathrm{s})$ & 120 & 60 & 10 \\
Number of stones & 8 & 8 & 8 \\
Abrasive grit type & Diamond & Silicon & Silicon \\
& & carbide & carbide \\
Grit size $(\mu \mathrm{m})$ & 149 & 107 & 30 \\
Bond type & Metallic & Vitrified & Vitrified \\
Size of honing stones & $3 \times 5 \times 80$ & $6 \times 6 \times 35$ & $6 \times 6 \times 35$ \\
$\quad(\mathrm{~mm} \times \mathrm{mm} \times \mathrm{mm})$ & & & \\
\hline
\end{tabular}


After texture generation, the honed liners were first cut in order to extract portions with dimensions of $127 \mathrm{~mm}$ (length) $\times$ $60 \mathrm{~mm}$ (width) $\times 2 \mathrm{~mm}$ (thickness) (Fig. 3), in order to facilitate optical measurements and to carry out the tribological tests and surface topography measurements.

\subsection{Surface topography measurements}

Surface topography measurements are carried out before tribological tests in order to ensure that all generated surface textures are at the same roughness level. A three-dimensional analysis was undertaken at the mid-height (i.e. at the mid dead center) of liner samples. Measurements were performed using a three-dimensional white light interferometer, WYKO 3300 NT (WLI). The surface topography area is determined by several tests showing the repeatability of the measurements at the different locations in the considered region. The surface is then sampled at $640 \times 480$ points with the same step scale of $1.94 \mu \mathrm{m}$ in the both $-x$ and $-y$ directions (the surface size is therefore $1.2 \mathrm{~mm} \times 0.93 \mathrm{~mm}$ ). The form component is removed from the acquired 3D data using least square method based on a cubic spline function. Furthermore, ISO standard 3D (ISO 25178-2 standard) roughness parameters $\left(S_{\mathrm{a}}, S_{\mathrm{k}}, S_{\mathrm{pk}}\right.$ and $\left.S_{\mathrm{vk}}\right)$ were extracted using a standard filtering $[20,21]$.

\subsection{Tribological tests}

Friction tests are carried out once for each honing configuration at an ambient temperature (around $24^{\circ} \mathrm{C}$ ) through a reciprocating ring-liner tribometer driven by a slider-crank mechanism with a stroke length of $80 \mathrm{~mm}$ (Fig. 4 and Fig. 6(a)). The contact surface is lubricated using $10 \mathrm{~W} 40$ synthetic oil ( $\mu_{D}$ equal to $0.08 \mathrm{Pas}$ at $40{ }^{\circ} \mathrm{C}$ ). The amount of the poured lubricant, at each test, is $2-3 \mathrm{ml}$.

Friction tests are mainly undertaken at a mixed lubrication regime (boundary lubrication can occur at the ends of the liner surface and hydrodynamic regime occurs at the middle part of the liner). However, the boundary lubrication regime is considered for a friction coefficient higher than $\sim 0.11$ (dry friction coefficient between cast iron (liner) and chromium (ring coating) is 0.14) [2,6] and hydrodynamic regime is specified for a friction coefficient lower than $\sim 0.06$ [22]. Two load levels ( $25 \mathrm{~N}$ and $50 \mathrm{~N}$ ) and different motor velocities are used to reach different average Sommerfeld numbers ( $S$ between $2 \times 10^{-6}$ and $2 \times 10^{-5}$ ) [23]. Before the tribological tests, a running-in period of $6 \mathrm{~min}$ is observed ( $3 \mathrm{~min}$ at $25 \mathrm{~N}$ and $3 \mathrm{~min}$ at $50 \mathrm{~N}$ ) at an average rotation velocity of $190 \mathrm{rpm}$. Fig. 5 shows the evolution of friction force (before signal filtering) during the running-in period with a transient zone at the beginning and a period of friction stability afterwards.

Due to a small contact surface between the ring and liner surface (the contact width is $4-5 \mathrm{~mm}$, the contact length $1.15 \mathrm{~mm}$ and therefore the contact area is $4-6 \mathrm{~mm}^{2}$ ), the contact pressure can reach up to $25 \mathrm{MPa}$. Concerning the ring characteristics, it consists of cast iron with chromium coating, its geometry is represented in Fig. 6 and its 3D arithmetic average roughness, Sa is $0.25 \pm 0.05 \mu \mathrm{m}$.

Friction coefficient is then calculated using the ratio between the average normal force $F_{\mathrm{N}}$ and the average tangential force $F_{\mathrm{T}}$, evaluated using strain gauges after filtering signal disturbances due to vibration using moving average filtering. This is a wellknown low-pass filter, one of the most used filtering methods in signal processing $[24,25]$. It is efficient for reducing noise while keeping the main features of the signal [25]. The method consists of averaging a number of points $(N)$ from the input signal $(\mathrm{x}(\mathrm{i}))$ to obtain the output signal, using the following formula [24,25](2) :

$y(i)=\frac{1}{N} \sum_{k=0}^{N-1} x(i-k)$

To filter correctly the input signal, $\mathrm{N}$ have to be properly chosen [24]. An example of a friction force filtered signal, using a moving average filter with $N=51$, is shown in Fig. 7. Here, the noise (high

Table 2

Kinematic honing operating conditions.

\begin{tabular}{lcccccc}
\hline Pattern type & $\boldsymbol{R} \mathbf{1}(\mathbf{m m})$ & $\boldsymbol{R} \mathbf{2}(\mathbf{m m})$ & $\boldsymbol{X / 2}(\mathbf{m m})$ & $\boldsymbol{Y} / \mathbf{2}(\mathbf{m m})$ & $\boldsymbol{R m}(\mathbf{m m})$ & $\boldsymbol{X} / \boldsymbol{Y}$ \\
\hline BC & 14.18 & 14.18 & 14.18 & 14.18 & 14.18 & 1.00 \\
SC & 7.25 & 7.25 & 7.25 & 7.25 & 7.25 & 1.00 \\
BTE & 10.00 & 22.40 & 16.20 & 11.66 & 13.93 & 1.39 \\
STE & 4.40 & 14.50 & 9.45 & 5.75 & 7.60 & 1.64 \\
BLE & 21.78 & 9.72 & 11.34 & 15.75 & 13.55 & 0.72 \\
SLE & 14.29 & 4.34 & 5.68 & 9.31 & 7.49 & 0.61 \\
\hline
\end{tabular}

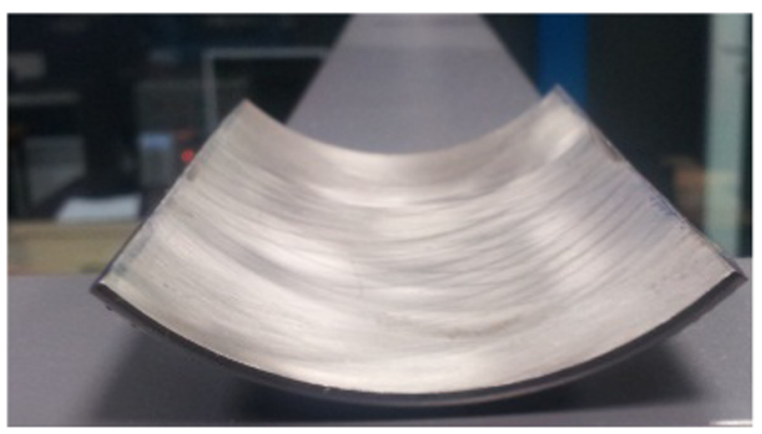

Fig. 3. Specimen cut from cylinder liner.

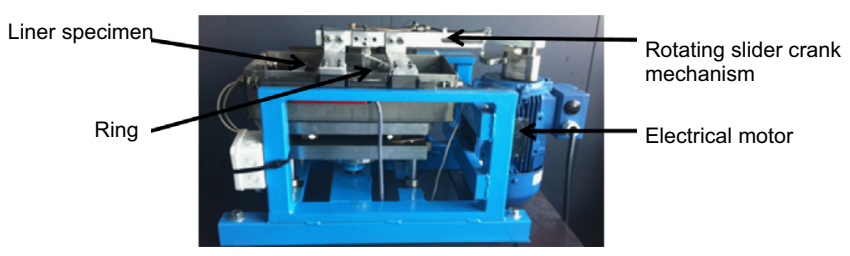

Fig. 4. Reciprocating ring-liner tribometer. a

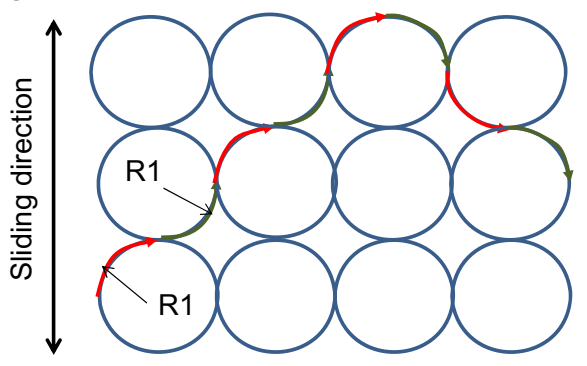

b

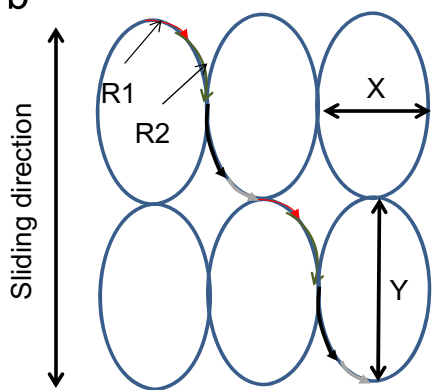

C

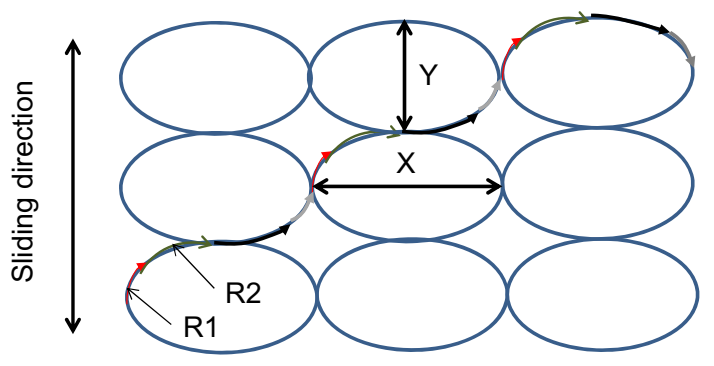

Fig. 2. Description of the honing kinematics for (a) circular (BS, SC), (b) longitudinal ellipse (SLE, BLE), (c) transverse ellipse texture (BTE, STE). 
frequencies) is removed while maintaining the gauge signal global behavior. The inversion zones of the liner, where the absolute value of sliding velocity is the lowest (before the sliding direction change), and the central zone of the liner, where absolute value of sliding velocity reaches a maximum value (before decreasing), are clearly identified (Fig. 7.(b)). Afterwards, the average friction force is calculated from the absolute value of the filtered signal.

\section{Results and discussions}

The analysis of the experimental results is based on the characterization of the surface finish and surface texture. It is used to evaluate the impact of the surface patterns anisotropy and its size on ring-liner friction performances. Then, the surface frictional performances are evaluated using tribological tests. Finally, the correlation between surface texture and friction surface performance is discussed in order to propose an innovative low-friction surface texture.

\subsection{Surface aspect observations}

The surface textures of engine liners are examined for each honing operating conditions. Fig. 8 shows the aspect of the different surface patterns (circles, transverse ellipses and longitudinal ellipses) at two different size levels. Globally, the morphology of textures (between circles, longitudinal and transverse ellipses) can be differentiated. Here, longitudinal ellipses consist mainly of vertical grooves whereas transverse ellipses mainly

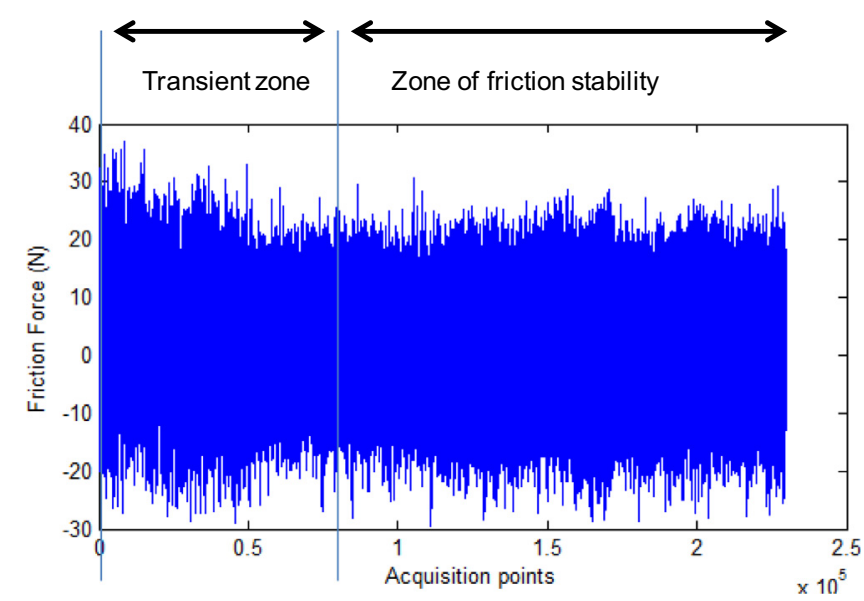

Fig. 5. Evolution of friction during running-in with a normal force of $50 \mathrm{~N}$ (unfiltered signal). consist of horizontal grooves. However, due to the "polishing phenomena", some grooves appear quite erased for both circular and longitudinal small ellipses (Fig. 8a1 and Fig. 8b1). Concerning HSH texture (Fig. 8d), cross-hatched grooves with a honing angle of $\sim 130^{\circ}$ can be clearly observed.

\subsection{D surface roughness comparison}

Fig. 9 represents the 3D surface roughness $\left(S_{\mathrm{a}}, S_{\mathrm{k}}, S_{\mathrm{pk}}\right.$ and $\left.S_{\mathrm{vk}}\right)$ of each surface texture morphology, according to ISO 25178-6 standard [4]. $S_{a}$ is the arithmetic roughness and represents the average global roughness. $S_{\mathrm{k}}, S_{\mathrm{pk}}$ and $S_{\mathrm{vk}}$ are the 3D equivalent ISO 13565-2 standard functional parameters standard and based on the bearing curve $[4,20,26]$ :

1. $S_{\mathrm{pk}}$ is the reduced peak height, average height of the protruding peaks above the roughness core profile.

2. $S_{\mathrm{k}}$ is the depth of the roughness core profile.

3. $S_{\mathrm{vk}}$ is the reduced valley depths, average depth of the protruding valleys below the roughness core profile.

The Fig. 9 demonstrates that the surface roughness is at the same order for all the novel textures samples taking into account the standard deviation. Therefore, friction performances should be affected essentially by lateral surface texture when the novel surfaces textures are compared together.

However, HSH surface, i.e. the surface taken as reference, presents a lower valley depth $(\sim 15 \%)$ as shown in Fig. $9\left(S_{\mathrm{vk}}\right.$ parameter). Then, HSH friction that will be considered here for comparison with novel textures friction will be slightly lower than expected if HSH surface has the same valleys depth as the novel surface textures $[4,9]$.

\subsection{Frictional performances}

Fig. 10 represents the friction coefficient (COF) evolution as a function of the average Sommerfeld number $(S)$ for the different texture anisotropies. For $R m \sim 7.5 \mathrm{~mm}$ (Fig. 10(a)), COF is reduced significantly when $S$ is relatively high (when $S>1 \times 10^{-5}$ ) for SC and SLE textures compared to STE texture. Here, the COF difference is not important between circles and longitudinal ellipse textures. For $R m \sim 14 \mathrm{~mm}$ (Fig. 10(b)), the COF variations between each texture pattern can be easily observed for relatively high values of $S$ $\left(S>1 \times 10^{-5}\right)$. COF is the lowest for longitudinal ellipses (BLE) and is the highest for transverse ellipses (BTE). This can be explained by the fact that, in hydrodynamic regime, friction is mainly improved when textured surface grooves are oriented in the sliding direction as the case of the (BLE) texture [2]. In other words, friction behavior a

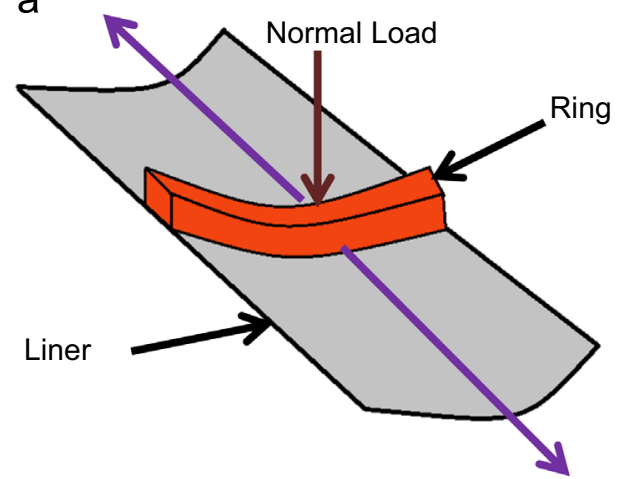

b

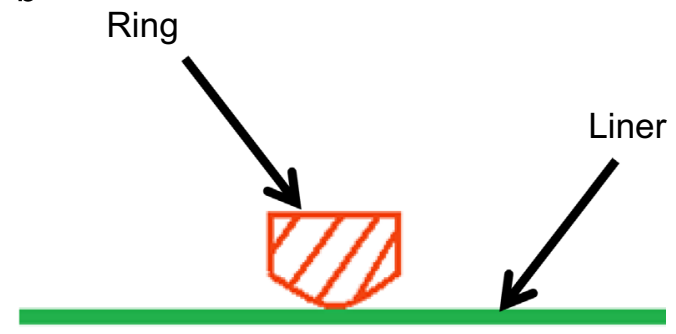

Reciprocating motion

Fig. 6. (a) Representation of the ring-liner contact, (b) Sectional view of ring-liner contact. 
a

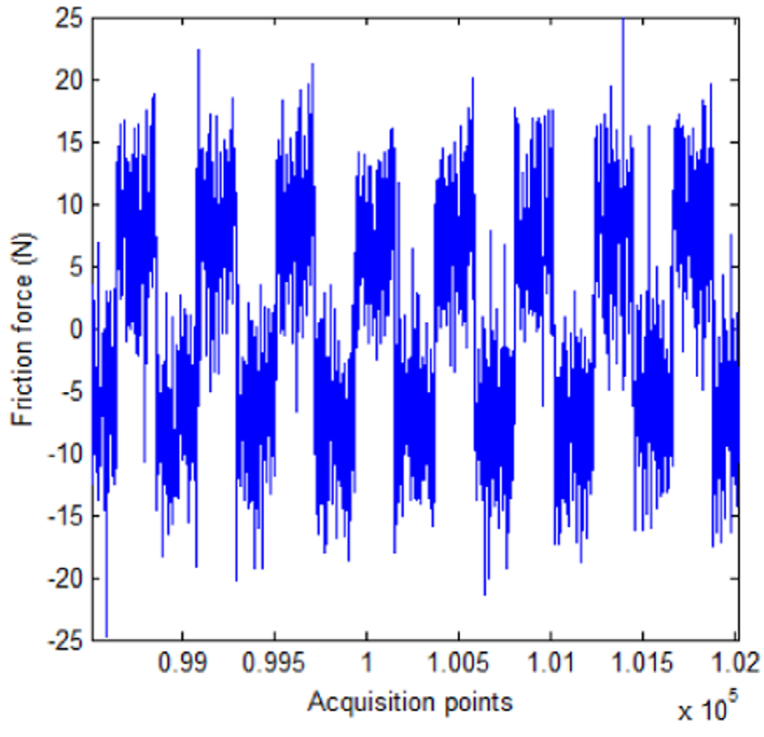

b

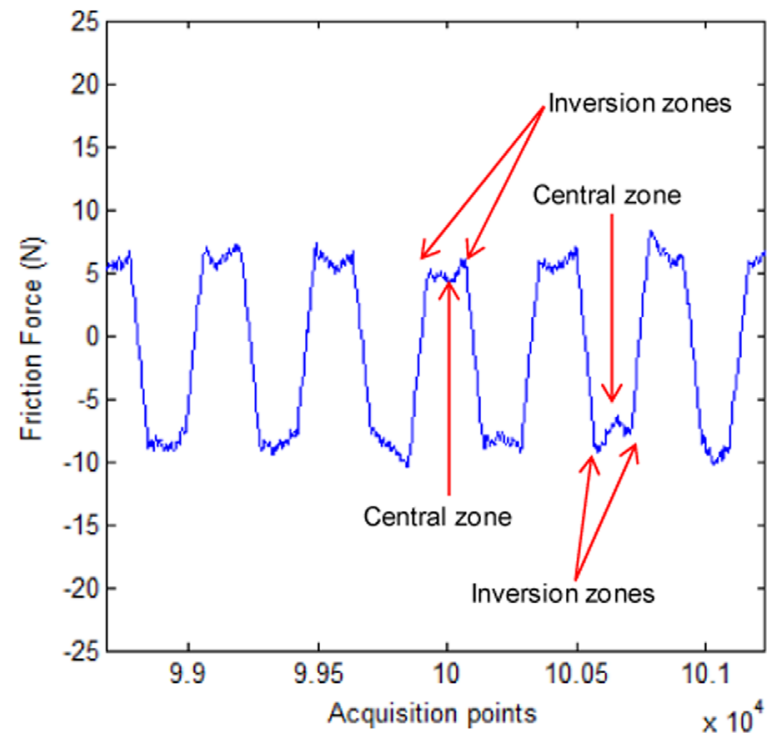

Fig. 7. Friction force (a) Initial signal (b) and filtered signal (using a moving average filter with $N=51$ ).

depends both on the lubrication regime and groove orientation. According to Yuan et al [3], mainly the longitudinal texture orientations enable to reduce friction coefficient in mixed and hydrodynamic regimes. So, as shown by Costa and Hutchings, these texture orientation enable to a better lubrication with a better oil motion, contrary to the transverse textures [27].

When $S$ is relatively low (i.e. lubrication conditions close to the boundary regime), there are no significant differences between the different texture patterns. It can be explained by the fact that curvilinear honed surface textures due to honing kinematics contain mainly horizontal grooves at the top and bottom dead center and where the sliding velocity is relatively low. The transversal orientation of grooves contributes to increase friction force in hydrodynamic and mixed regimes but are more beneficial (better lubrication and lower friction coefficient) in boundary lubrication due to a better oil retention at a low Sommerfeld number [3].

Fig. 11 compares COF of the all textures for $S=1.6 \times 10^{-5}$, which corresponds to a rotation velocity of $290 \mathrm{rpm}$ and a normal force of $20 \mathrm{~N}$. These conditions correspond to high values of $S$ in mixed lubrication regime, in which the texture effect on friction reduction is the most important [28]. It confirms the previous remarks and shows that BLE textures are the most efficient in terms of friction performances. These performances have to be compared with an industrial texture.

\subsection{Friction improvement compared to conventional HSH surface texture}

Afterwards, in order to evaluate their industrial interest, the friction performances of each texture are compared with an industrial HSH texture at comparable operating conditions $\left(S \sim 1.6 \times 10^{-5}\right)$, for high values of $S$ in the mixed lubrication regime, where texture effect can be more easily observed [2,28]. The results are shown in Fig. 12. Here the relative friction reduction (\%) is calculated using the following formula:

COF_reduction $(\%)=\frac{\mathrm{COF}_{\mathrm{HSH}}-\mathrm{COF}_{\mathrm{TEXTURE}}}{\mathrm{COF}_{\mathrm{HSH}}} \times 100$

Where COF $_{\text {TEXTURE }}$ is the friction coefficient of the considered texture, and $\mathrm{COF}_{\mathrm{HSH}}$ the friction coefficient of an $\mathrm{HSH}$ industrial texture.
It shows a sensible friction reduction for BLE textures of around 9\%. A low COF reduction (around 3\%) is noticed for SC. The other textures seem to be not interesting in terms of COF reduction in the mixed lubrication regime. It can be explained by their orientation (for transverse ellipses) in which the lubricant flow is opposite to groove orientation or/and "polishing phenomena" (for SLE textures) with lower groove depth which is not beneficial to good lubrication conditions [2].

For BLE textures, the results are very promising for friction reduction and then the improvement of the efficiency of combustion engines. For example, Howell-Smith showed an engine power gain up to $4 \%$ for laser etched liner in comparison to industrial honed liners [8]. Moreover, the process which generates these textures is not very expensive compared to an innovative finish processes for cylinder liners such as Laser surface texturing $[6,29]$ or bore spray coating [30]. In fact, it is the same process as the mechanical abrasive honing process with different kinematics.

This promising innovative surface texture must be validated in real combustion engine conditions and has the advantage, like abrasive honed textures, to be quite easily manufactured.

\subsection{Discussion about the most influent texture pattern parameters on friction reduction}

In order to see which aspect surface texture parameter influences the friction reduction most and to optimize the honing kinematics, the linear correlation method is used to observe the link between surface texture and its functionality [31-33]. From this method, a correlation coefficient (between 0 and 1) is calculated, which correlates the evolution between two parameters (a texture feature and friction coefficient). Here, the correlation is considered strong when the absolute value of the correlation coefficient is higher than 0.70 . When the correlation coefficient value is positive, it means that the texture parameter leads to an increase in the friction. On the other hand, when the correlation coefficient value is negative, it means that the texture parameter is contributing more to reduce the friction. Six parameters which describe the aspect of the proposed texture are considered:

1. $R m$, the average radius.

2. $R 1$, the first ellipse radius (perpendicular to the sliding direction). 
a1

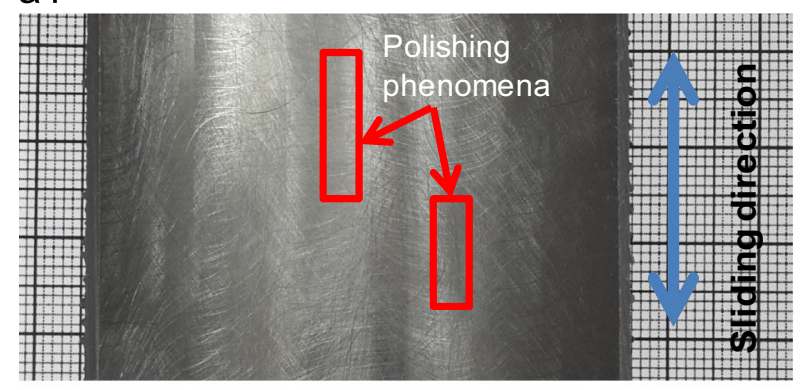

b1

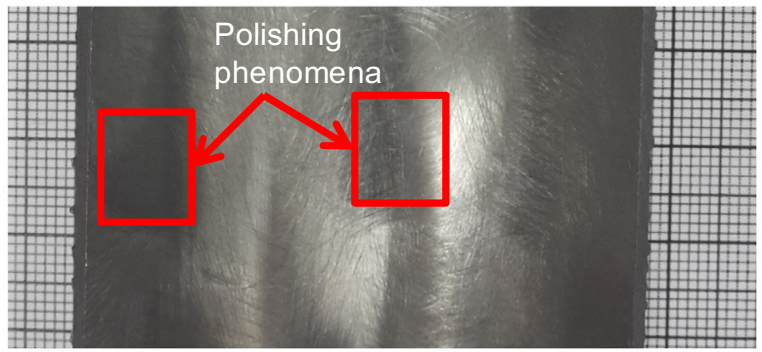

c1

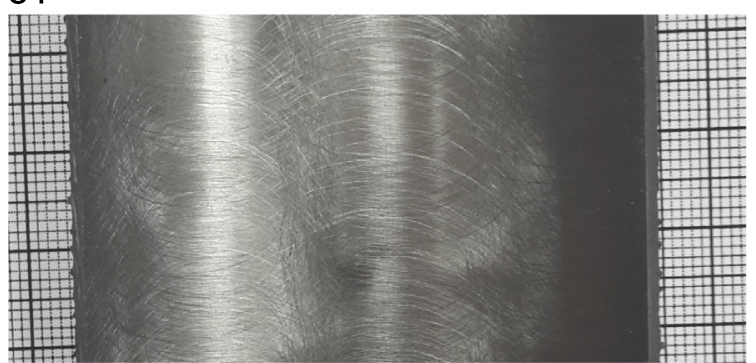

a2

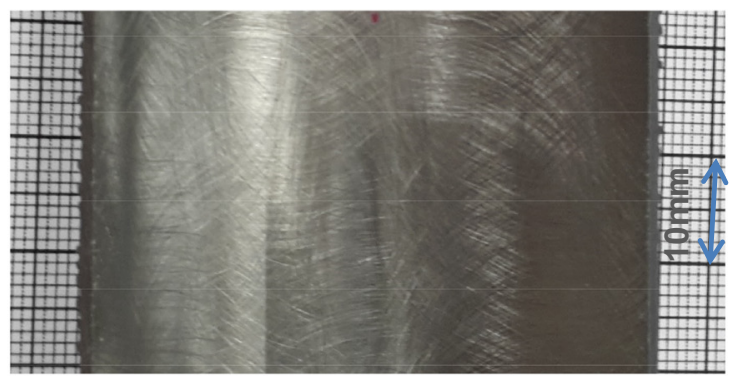

b2

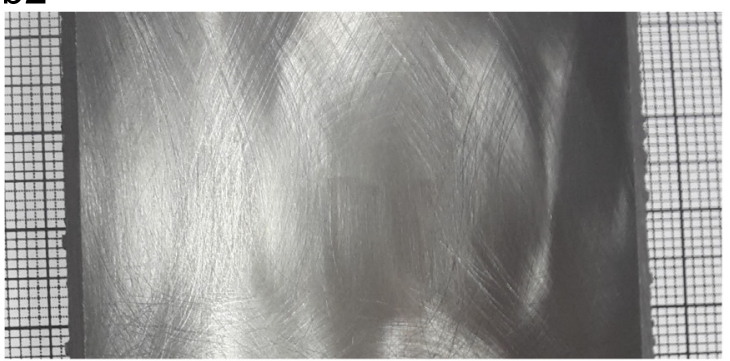

c2

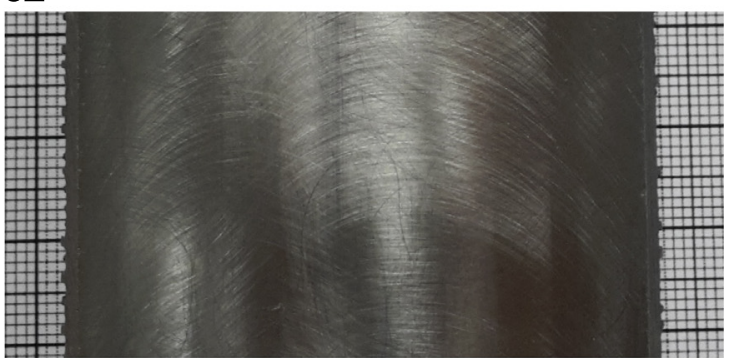

d

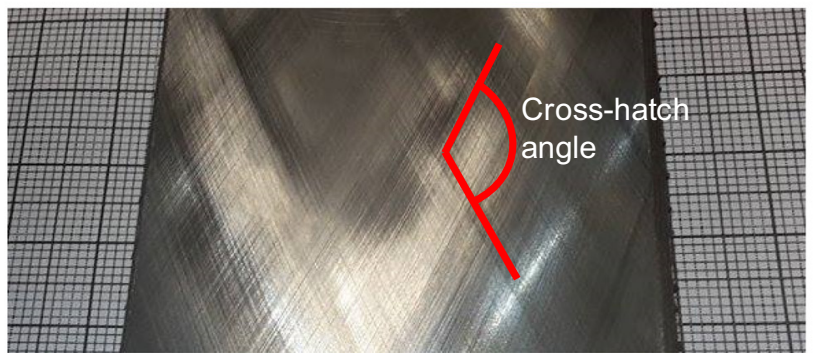

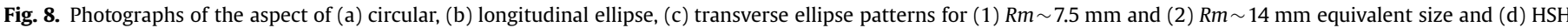
surface.

3. $R 2$, the second ellipse radius (in the sliding direction).

4. $X / 2$, the ellipse mid-width (perpendicular to the sliding direction).

5. $Y / 2$, the ellipse mid-length (in the sliding direction).

6. $X / Y$, the aspect ratio.

The obtained correlation coefficients between the aspect texture pattern and friction coefficient are shown in Fig. 13. Firstly, it shows that patterns average radius $(\mathrm{Rm})$ has a low influence on the friction reduction, which means that pattern size has not a high contribution on friction performances.

Secondly, the correlation coefficients of $X / Y, X, Y R 1$ and $R 2$ parameters show that groove orientation has an important influence on friction reduction. In particular, the ellipse orientation, characterized by the $X / Y$ parameter, is the most relevant parameter describing the friction variations. In fact, $X / Y$ increase (to obtain a more transverse texture), leads to an increase in COF and

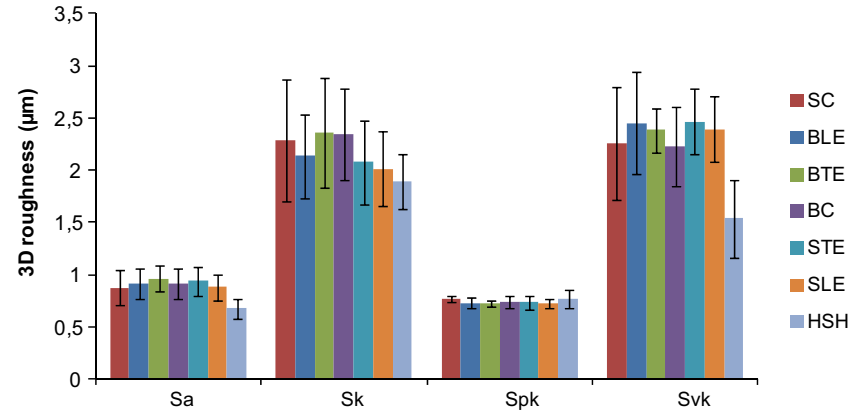

Fig. 9. 3D roughness amplitude using $S_{\mathrm{a}}, S_{\mathrm{k}}, S_{\mathrm{pk}}$ and $S_{\mathrm{vk}}$ parameter for the different textures.

conversely. Concerning $X$ and $Y$ parameters (texture width and texture length respectively), they have a sensitive influence on the COF increase and COF reduction respectively. Otherwise, the 
a

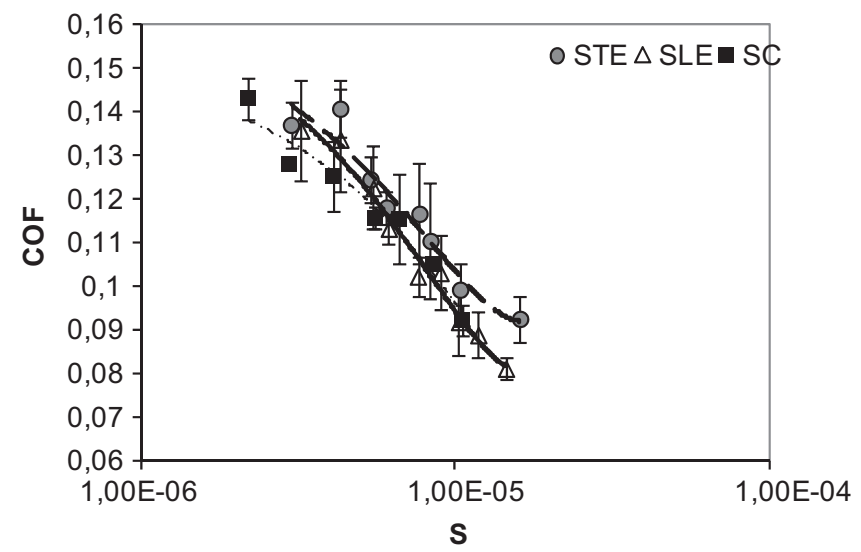

b

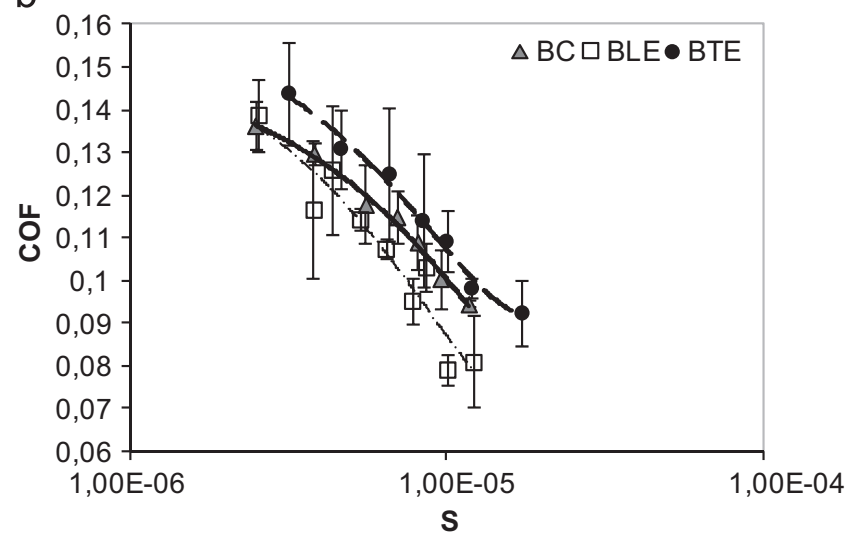

Fig. 10. Evolution of friction coefficient (COF) in function of $S$; (a) for small size patterns $(R m \sim 7.5 \mathrm{~mm})$ : SC, SLE and STE; for (b) big size patterns ( $R m \sim 14 \mathrm{~mm})$ : BC, BLE and BTE.

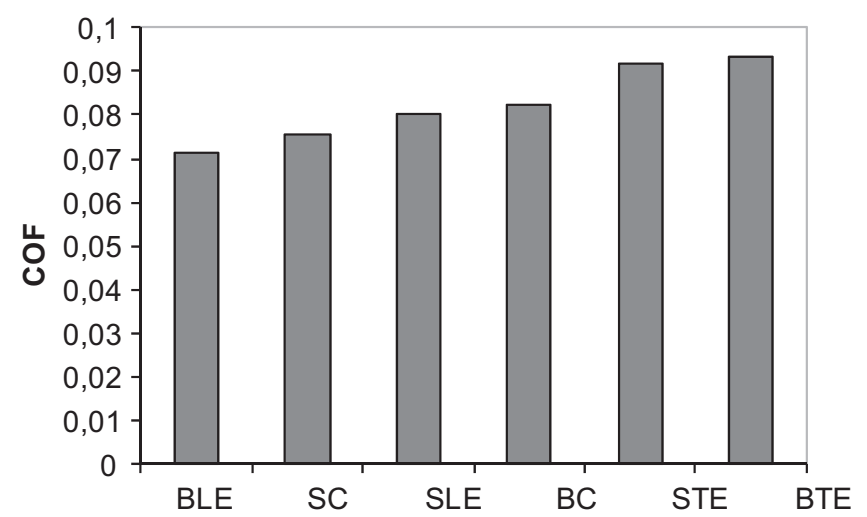

Fig. 11. Comparison of friction coefficient (COF) at $S=1.6 \times 10^{-5}$ between the different textures.

longitudinal and transversal grooves curvatures, respectively characterized by $R 1$ and $R 2$ aspect parameters, affect significantly (in comparison with $X$ and $Y$ parameters) the friction coefficient.

Here the effect of texture parameters on COF variations can be explained by the scale effect. Some studies have shown the importance of the scale on friction performance of liner surfaces $[22,33,34]$. In this study the scale depends on the orientation of sliding motion and the contact area. Here the contact width is about $5 \mathrm{~mm}$ and the textures with a value of $R 2$ and $X / 2$ far to the contact width (BC, BTE and STE) contribute the most to increase friction performances for $S=1.6 \times 10^{-5}$.

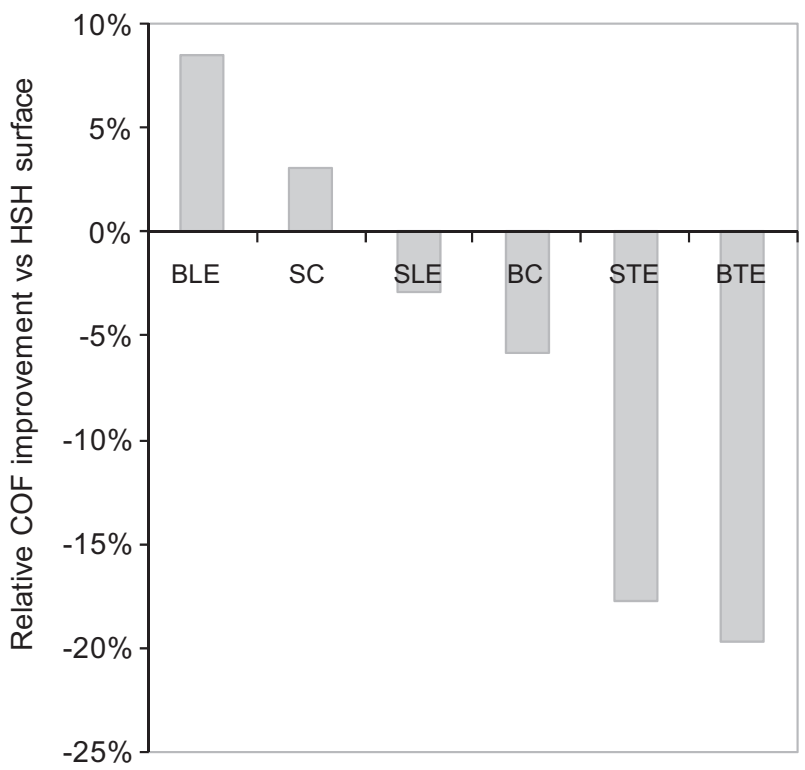

Fig. 12. Relative COF improvement for the different surfaces in comparison with an HSH surface.

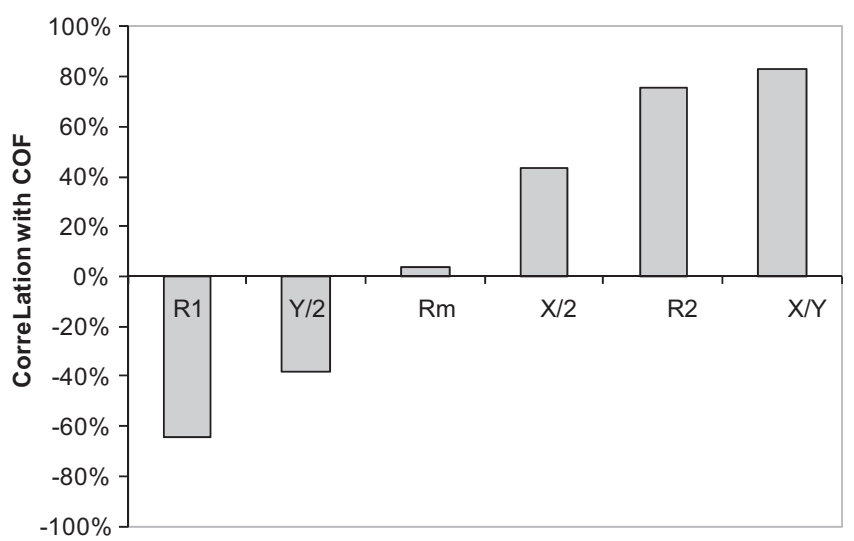

Fig. 13. Linear correlation between surface texture aspect parameters and friction coefficient.

\section{Conclusions}

The present study compares friction performances (through a reciprocating tribometer) of different innovative texture patterns (circles and ellipses at different sizes and orientations) generated by abrasive honing process. It also identifies the most influent geometrical texture parameters on friction variations.

Results show that BLE (big size longitudinal ellipse pattern) surface texture leads to the best reduction of the COF for higher values of $S$ in mixed lubrication regime (i.e. lubrication conditions close to the hydrodynamic regime), compared to the industrial surface (HSH) surface texture. This is due to the vertical orientation (parallel to ring motion) of longitudinal ellipse patterns and the scale effect which enable a better lubricant flow for ring-liner contact.

In an industrial context, this is a promising result in terms of engine performances and process costs since the process that generates these textures is similar to that widely used actually in automotive industry. However, the results have to be confirmed in real combustion engine conditions and the honing kinematics can be further optimized for lower friction losses. 


\section{Acknowledgments}

The authors which to thank Renault company (Powertrain Process Division) for the support concerning the development of the innovative honing prototype machine.

\section{References}

[1] Schmid J, Hoen T, Stumpf W. Less wear and oil consumption through Helical Slide Honing of Engines by Deutz. MTZ worldwide 2009;70:46-51.

[2] Yousfi M, Mezghani S, Demirci I, El Mansori M. Smoothness and plateauness contributions to the running-in friction and wear of stratified helical slide and plateau honed cylinder liners. Wear 2015;332-333:1238-47. http://dx.doi.org/ 10.1016/j.wear.2014.11.011.

[3] Yuan S, Huang W, Wang X. Orientation effects of micro-grooves on sliding surfaces. Tribol Int 2011:44:1047-54. http://dx.doi.org/10.1016/j.triboint 2011.04.007.

[4] Mezghani S, Demirci I, Yousfi M, El Mansori M. Mutual influence of crosshatch angle and superficial roughness of honed surfaces on friction in ring-pack tribosystem. Tribol Int 2013;66:54-9. http://dx.doi.org/10.1016/j.triboint.2013.04.014.

[5] Michail SK, Barber GC. The effects of roughness on piston ring lubrication-Part II: the relationship between cylinder wall surface topography and oil film thickness. Tribol Trans 1995;38:173-7. http://dx.doi.org/10.1080/10402009508983394.

[6] Tomanik E. Friction and wear bench tests of different engine liner surface finishes. Tribol Int 2008;41:1032-8. http://dx.doi.org/10.1016/j.triboint.2007.11.019.

[7] Schmid J. Honing technology for optimal cast-iron cylinder liners. Engine Technol Int 1999;1/2:108-9.

[8] Howell-Smith S, Rahnejat H, King PD, Dowson D. Reducing in-cylinder parasitic losses through surface modification and coating. Proc Inst Mech Eng Part D J Automob Eng 2014;228:391-402. http://dx.doi.org/10.1177/0954407013512626.

[9] Yousfi M, Mezghani S, Demirci I, Mansori M El. Mutual effect of groove size and anisotropy of cylinder liner honed textures on engine performances. Adv Mater Res 2014;966-967:175-83. http://dx.doi.org/10.4028/www.scientific. net/AMR.966-967.175.

[10] Pawlus P, Cieslak T, Mathia T. The study of cylinder liner plateau honing process. J Mater Process Technol 2009;209:6078-86. http://dx.doi.org/ 10.1016/j.jmatprotec.2009.04.025.

[11] Goeldel B, Etude et mise en œuvre d'un moyen flexible pour le rodage de carter cylindre de moteur à combustion interne ( $\mathrm{PhD}$ thesis). Arts et Métiers, Paris Tech; 2013.

[12] Lu X, Khonsari MM. An experimental investigation of dimple effect on the stribeck curve of journal bearings. Tribol Lett 2007;27:169-76. http://dx.doi. org/10.1007/s11249-007-9217-x.

[13] Yu H, Wang X, Zhou F. Geometric shape effects of surface texture on the generation of hydrodynamic pressure between conformal contacting surfaces. Tribol Lett 2009;37:123-30. http://dx.doi.org/10.1007/s11249-009-9497-4.

[14] Kovalchenko A, Ajayi O, Erdemir A, Fenske G. Friction and wear behavior of laser textured surface under lubricated initial point contact. Wear 2011;271:1719-25. http://dx.doi.org/10.1016/j.wear.2010.12.049.

[15] Caciu C, Decencière E, Jeulin D. Parametric optimization of periodic textured surfaces for friction reduction in combustion engines. Tribol Trans 2008;51:533-41. http://dx.doi.org/10.1080/10402000802065337.

[16] Tang W, Zhou Y, Zhu H, Yang H. The effect of surface texturing on reducing the friction and wear of steel under lubricated sliding contact. Appl Surf Sci 2013;273:199-204. http://dx.doi.org/10.1016/j.apsusc.2013.02.013.
[17] Braun D, Greiner C, Schneider J, Gumbsch P. Efficiency of laser surface texturing in the reduction of friction under mixed lubrication. Tribol Int 2014;77:142-7. http://dx.doi.org/10.1016/j.triboint.2014.04.012.

[18] Goeldel B, Voisin J, Dumur D, El Mansori M, Frabolot M. Flexible right sized honing technology for fast engine finishing. CIRP Ann-Manuf Technol 2013;62:327-30.

[19] Mezghani S, Demirci I, Yousfi M, El Mansori M. Running-in wear modeling of honed surface for combustion engine cylinderliners. Wear 2013;302:1360-9. http://dx.doi.org/10.1016/j.wear.2013.01.026.

[20] Yousfi M, Mezghani S, Demirci I, El Mansori M, Comparative study between 2D and 3D characterization methods for cylinder liner plateau honed surfaces, vol. 42. In: Proceedings of NAMRI/SME; 2014.

[21] NF EN ISO 25178-6. Etat de surface: Surfacique-Partie 6: Classification des méthodes de mesurage de l'état de surface; 2010.

[22] Demirci I, Mezghani S, Yousfi M, El Mansori M. Multiscale analysis of the roughness effect on lubricated rough contact. J Tribol 2014;136:011501. http: //dx.doi.org/10.1115/1.4025222.

[23] Ting LL. Development of a reciprocating test rig for tribological studies of piston engine moving components-part I: Rig design and piston ring friction coefficients measuring method. In: International congress and exposition. SAE technical papers 930685. Dearborn, MI, United States. p. 462-9; 1993. doi: $10.4271 / 930685$.

[24] Alessio E, Carbone A, Castelli G, Frappietro V. Second-order moving average and scaling of stochastic time series. Eur Phys J B-Condens Matter 2002;27:197-200. http://dx.doi.org/10.1140/epjb/e20020150.

[25] Mivule K, Turner C. Applying moving average filtering for non-interactive differential privacy settings. Proc Comput Sci 2014;36:409-15. http://dx.doi. org/10.1016/j.procs.2014.09.013.

[26] Dimkovski Z, Anderberg C, Ohlsson R, Rosén B-G. Characterisation of worn cylinder liner surfaces by segmentation of honing and wear scratches. Wear 2011;271:548-52. http://dx.doi.org/10.1016/j.wear.2010.04.024.

[27] Costa HL, Hutchings IM. Hydrodynamic lubrication of textured steel surfaces under reciprocating sliding conditions. Tribol Int 2007;40:1227-38. http://dx. doi.org/10.1016/j.triboint.2007.01.014.

[28] Suh M, Chae Y, Kim S, Hinoki T, Kohyama A. Effect of geometrical parameters in micro-grooved crosshatch pattern under lubricated sliding friction. Tribol Int 2010;43:1508-17. http://dx.doi.org/10.1016/j.triboint.2010.02.012.

[29] Bathe R, Sai Krishna V, Nikumb SK, Padmanabham G. laser surface texturing of gray cast iron for improving tribological behavior. Appl Phys A 2014;117:11723. http://dx.doi.org/10.1007/s00339-014-8281-y.

[30] Bobzin K, Ernst F, Zwick J, Schlaefer T, Cook D, Nassenstein K, et al. Coating bores of light metal engine blocks with a nanocomposite material using the plasma transferred wire arc thermal spray process. J Therm Spray Technol 2008;17:344-51. http://dx.doi.org/10.1007/s11666-008-9188-y.

[31] Rosen B-G, Anderberg C, Ohlsson R. Parameter correlation study of cylinder liner roughness for production and quality control. Proc Inst Mech Eng Part B J Eng Manuf 2008;222:1475-87. http://dx.doi.org/10.1243/09544054JEM1201.

[32] Rosen B-G, Anderberg C, Pawlus P, Thomas T. Alternative descriptions of roughness for cylinder liner production. J Mater Process Technol 2009;209:1936-42. http://dx.doi.org/10.1016/j.jmatprotec.2008.04.059.

[33] Yousfi M, Mezghani S, Demirci I, El Mansori M. Study on the relevance of some of the description methods for plateau-honed surfaces. Surf Topogr Metrol Prop 2013;2(014006):1-7. http://dx.doi.org/10.1088/2051-672X/2/1/014006.

[34] Demirci I, Mezghani S, Yousfi M, Zahouani H, Mansori M El. The scale effect of roughness on hydrodynamic contact friction. Tribol Trans 2012;55:705-12. http://dx.doi.org/10.1080/10402004.2012.694990. 